\title{
Laboratory survey and literature review of anaerobic bacteriology: foundations of a clinically orientated and evidence-based workup for anaerobic cultures
}

\author{
Bart Peeters ${ }^{1}$, Koen Magerman, Luc Waumans, Reinoud Cartuyvels * \\ Clinical Laboratory, Jessa Hospital, Hasselt, Belgium
}

\section{A R T I C L E I N F O}

\section{Article history:}

Received 17 March 2016

Received in revised form 2 June 2016

Accepted 5 June 2016

Available online 8 June 2016

\section{Keywords:}

Anaerobic bacteriology

Matrix-assisted laser desorption ionization

time-of-flight mass spectrometry

Anaerobic workup scheme

Laboratory survey

\begin{abstract}
A B S T R A C T
Since the introduction of matrix-assisted laser desorption ionization time-of-flight mass spectrometry (MALDITOF MS) in routine microbiology laboratories, identification of anaerobic bacteria has become easier. These increased possibilities provide new challenges concerning analytical workup and reporting of anaerobes. In February 2015 , an extensive web-based survey on pre-analytical, analytical and post-analytical procedures of anaerobic microbiology was sent to 53 Belgian, university and non-university hospital laboratories. Answers of 34 participating laboratories revealed a huge diversity in all analytical stages of anaerobic microbiology. Whether or not colony types were identified was mainly based on anatomical origin of the sample, colony morphology, and total number of different anaerobic isolates in the sample, while reporting of isolate results and performing anti-microbial susceptibility testing was mainly based on anatomical origin of the sample, number of different anaerobic isolates, and the identification of the anaerobic bacteria. These variety of workup procedures were mainly expert-based and have not been extensively clinically validated. For this reason, a standardized, clinically orientated, and feasible procedure for the workup of anaerobic cultures was developed, using MALDI-TOF MS identification, based upon literature data and existing guidelines.
\end{abstract}

(c) 2016 Elsevier Inc. All rights reserved.

\section{Introduction}

During the past decades, there has been a changing interest in anaerobic bacteria based upon the verification of their role as pathogens, efficacy of antibiotic treatment, and the elucidation of their virulence factors.

Extensive identification of anaerobic bacteria used to be time consuming or required expensive equipment such as high performance liquid chromatography, technical skills and experience (Jousimies-Somer et al., 2002). Since the introduction of matrix-assisted laser desorption ionization time-of-flight mass spectrometry (MALDI-TOF MS), reliable, fast, inexpensive and easy identification of anaerobic bacteria suddenly became feasible for routine microbiology laboratories (Barba et al., 2014; Biswas \& Rolain, 2013; Croxatto et al., 2012; Hsu \& Burnham,

Abbreviations: AST, Anti-microbial susceptibility testing; BSAC, British Society for Antimicrobial Chemotherapy; CASFM, Comité de l'Antibiogramme de la Société Française de Microbiologie; CLSI, Clinical and Laboratory Standards Institute; ESCMID, European Society of Clinical Microbiology and Infectious Diseases; EUCAST, European Committee on Antimicrobial Susceptibility Testing; ID, Identification; MALDI-TOF MS, Matrix-assisted laser desorption ionization time-of-flight mass spectrometry; MeSH, Medical subject heading; rRNA, Ribosomal ribonucleic acid.

* Corresponding author. Tel: +32 11 338241; fax: +32 11309750.

E-mail addresses: bart.1.peeters@uzleuven.be, bartpeeters13@hotmail.com (B. Peeters), koen.magerman@jessazh.b (K. Magerman), luc.waumans@jessazh.be (L. Waumans), reinoud.cartuyvels@jessazh.be (R. Cartuyvels).

${ }^{1}$ Present address: Department of Laboratory Medicine, University Hospital, Leuven, Belgium.
2014; Patel, 2015). Through this, a theoretically unlimited amount of information on anaerobic microorganisms present in clinical samples can be gathered, posing new challenges for the microbiology laboratories. Questions about clinical relevance of different anaerobic bacteria arise. Consequently, the need to perform identification or anti-microbial susceptibility testing (AST) and to report anaerobic bacteria to the clinicians is questioned. Currently there are few guidelines suggesting feasible workup schemes for anaerobic cultures using MALDI-TOF MS identification. In 1992, 1995 and 2008, Goldstein et al. published surveys regarding basic anaerobic culture and susceptibility testing methods in hospitals from the United States (Goldstein et al., 1992, 1995, 2008). They concluded that many laboratories were performing anaerobic cultures (especially blood cultures) and AST (Goldstein et al., 1992, 2008). However, culture and workup procedures were not standardized and in dire need of improvement (Goldstein et al., 1992, $1995,2008)$. In order to make anaerobic bacteriology more clinically relevant, Goldstein et al. recommend presumptive identification of important pathogens within 24 hours and AST results within 48 hours (Goldstein et al., 1992).

This article summarized current practices of routine microbiology laboratories in Belgium regarding identification, reporting and AST of anaerobic bacteria by means of a web-based survey. Survey results were compared with recommendations of guidelines and literature. Laboratories were not questioned about basic anaerobic incubation practices like the use of indicators in jars ensuring an anaerobic 
Table 1

Acceptance and rejection of different sample types.

\begin{tabular}{|c|c|c|c|c|c|}
\hline \multirow{2}{*}{$\begin{array}{l}\mathrm{N}=34(100 \%) \\
\text { Generally accepted samples }\end{array}$} & \multicolumn{4}{|c|}{ Anaerobic culture is performed } & \multirow[t]{2}{*}{ Refused } \\
\hline & Always & After contacting clinician, if not requested & If requested by clinician & If requested and justified by clinician & \\
\hline Blood & $27(79)$ & $0(-)$ & $7(21)$ & $0(-)$ & $0(-)$ \\
\hline Ascites fluid & $25(73)$ & $1(3)$ & $8(23)$ & $0(-)$ & $0(-)$ \\
\hline Abdominal fluid & $24(71)$ & $0(-)$ & $10(29)$ & $0(-)$ & $0(-)$ \\
\hline Pleural fluid & $21(62)$ & $2(6)$ & $10(29)$ & $1(3)$ & $0(-)$ \\
\hline Joint fluid & $20(59)$ & $1(3)$ & $12(35)$ & $0(0)$ & $1(3)$ \\
\hline CSF & $16(47)$ & $2(6)$ & $8(23)$ & $5(15)$ & $3(9)$ \\
\hline Deep aspirate/biopsy & $17(50)$ & $5(15)$ & $12(35)$ & $0(-)$ & $0(-)$ \\
\hline Deep wound swab & $11(32)$ & $3(9)$ & $18(53)$ & $1(3)$ & $1(3)$ \\
\hline Sinus aspirate & $17(50)$ & $1(3)$ & $13(38)$ & $2(6)$ & $1(3)$ \\
\hline \multicolumn{6}{|l|}{ Generally rejected samples } \\
\hline Bronchial aspirate & $1(3)$ & $0(-)$ & $2(6)$ & $6(18)$ & $25(73)$ \\
\hline Sputum & $0(-)$ & $0(-)$ & $0(-)$ & $5(15)$ & $29(85)$ \\
\hline NP swab & $0(-)$ & $0(-)$ & $3(9)$ & $3(9)$ & $28(82)$ \\
\hline Urine & $0(-)$ & $0(-)$ & $0(0)$ & $7(21)$ & $27(79)$ \\
\hline Vaginal swab & $0(-)$ & $2(6)$ & $2(6)$ & $5(15)$ & $25(73)$ \\
\hline Cervical swab & $1(3)$ & $1(3)$ & $5(15)$ & $4(12)$ & $23(68)$ \\
\hline Catheter tip & $2(6)$ & $1(3)$ & $2(6)$ & $4(12)$ & $25(73)$ \\
\hline Superficial wound swab & $6(18)$ & $2(6)$ & $4(12)$ & $3(9)$ & $19(56)$ \\
\hline
\end{tabular}

$\mathrm{CSF}=$ cerebrospinal fluid; $\mathrm{NP}=$ nasopharyngeal

environment, maximum time of oxygen exposure before incubation, reopening of jars, and the use of pre-reduced agar plates or culture medium used for primary incubation. This could be the subject of an updated web-based survey.

\section{Material and methods}

A Web-based survey with 15 multiple-choice questions on the preanalytical, analytical and post-analytical procedures in anaerobic bacteriology was sent by e-mail to 53 Belgian laboratories, in university and non-university hospitals (mean of 900 beds, range from 200 to 2000 beds). For the composition of the survey questions, CLSI guidelines (M56A; M11-A8; M100-S25), the Wadsworth-KTL Anaerobic Bacteriology Manual and the Manual of Clinical Microbiology were consulted (Clinical and Laboratory Standards Institute, 2012, 2014, 2015; Jousimies-Somer et al., 2002; Versalovic et al., 2011).

Relevant literature was identified using the MeSH Database on the PubMed website. The search terms used were: "Clinical anaerobic microbiology", "Anaerobic bacteria and clinical relevance", "Workup anaerobic microbiology", "Anaerobic infections and clinical relevance", "Anaerobic bacteria and susceptibility", "Anaerobic infections and management", "Anaerobic bacteria and virulence", "Anaerobic bacteria and anti-microbial susceptibility testing", "Anaerobic infections and outcome". Additionally "PubMed Clinical Queries" were used (from 1966; http://www.ncbi. nlm.nih.gov/entrez/query.fcgi: Systematic Reviews; Clinical Queries using Research Methodology Filters). UpToDate Online version 23.3 (2015) was checked for these terms: "Anaerobic infections", "Anaerobic microbiology". Following reference works and handbooks were consulted: Clinical Microbiology Procedures Handbook - Section 4 Anaerobic Bacteriology (referred to as 'Garcia') (Garcia \& Hall, 2010), Wadsworth-KTL Anaerobic Bacteriology Manual (referred to as 'Wadsworth') (Jousimies-Somer et al., 2002) and the Manual of Clinical Microbiology (Referred to as 'Versalovic') (Versalovic et al., 2011).

\section{Results}

Overall, 34 laboratories participated in this survey: five university and 29 non-university laboratories. The other 19 laboratories did not answer the invitation e-mail and did not participate. All responding laboratories had facilities (anaerobic jars, cabinets) to culture and isolate anaerobic bacteria. Results of the seven most relevant questions are discussed in detail. Results of the other questions are presented in the appendices section (Figs A.1-A.5 and Tables A.1-A.2).

\subsection{Which samples are accepted/rejected for culture of anaerobic bacteria?}

All participating laboratories performed anaerobic culture on certain sample types while others were refused (Table 1 ).

\subsection{Does your laboratory use specific anaerobic collection or transport media?}

Most participating laboratories (65\%) did not use defined collection or transport media for anaerobes. A combination of Amies swab systems, syringes or anaerobic blood culture bottles was used in some laboratories (29\%). Only a few laboratories used specific tubes, vials or jars containing a pre-reduced transport medium with reducing agents (6\%). A swab in liquid Amies medium was the most used transport medium for anaerobic samples (21\%).

3.3. What is the current rationale in your laboratory for identifying, reporting and AST of anaerobic bacteria?

The decision whether a colony on an anaerobic culture medium should be identified, reported or tested for susceptibility was mainly based on anatomical origin of the sample (normally sterile body sites) and the number of anaerobic isolates (up to 2 anaerobic isolates). Colony morphology played an important role in the decision whether anaerobic growth should be identified. The kind of isolated anaerobic bacteria (Bacteroides fragilis group, other Gram-negative anaerobic bacteria and histotoxic Clostridium spp.) was also decisive for reporting and performing AST (Tables 2-4).

\subsection{Which identification method is used for anaerobic bacteria in your laboratory?}

In this survey $68 \%$ of the laboratories used MALDI-TOF MS technology for routine identification of anaerobic isolates. Only 31\% of the laboratories had access to 16S rRNA gene sequencing and none of them used this method for routine identification of anaerobes. Nearly all laboratories (91\%) used Gram staining for presumptive identification of anaerobic bacteria and in a single laboratory (3\%) this was the only identification method for anaerobes. Most laboratories used selective/ differential agars (63\%) or biochemical identification techniques (57\%) but these methods were rarely used for routine identification (6\% and $23 \%$, respectively) (Fig. 1). 
Table 2

Rationale for identifying, reporting and performing AST of anaerobic bacteria.

\begin{tabular}{|c|c|c|c|}
\hline & $\begin{array}{l}\text { Performing full ID } \\
\mathrm{N}=34(100 \%)\end{array}$ & $\begin{array}{l}\text { Reporting full ID } \\
\mathrm{N}=34(100 \%)\end{array}$ & $\begin{array}{l}\text { Performing AST } \\
\mathrm{N}=34(100 \%)\end{array}$ \\
\hline Samples from normally sterile body sites & $19(56)$ & $18(53)$ & $13(38)$ \\
\hline Number of anaerobic isolates (Table 3) & $13(38)$ & $14(41)$ & $10(29)$ \\
\hline Kind of anaerobic bacteria (Table 4) & $0(-)$ & $14(41)$ & $13(38)$ \\
\hline Colony morphology & $13(38)$ & $0(-)$ & $0(-)$ \\
\hline Always & $1(3)$ & $10(29)$ & $6(18)$ \\
\hline Ratio (an)aerobic isolates & $6(18)$ & $6(18)$ & $4(12)$ \\
\hline Other & $3(9)$ & $3(9)$ & $3(9)$ \\
\hline Never & $0(-)$ & $0(-)$ & $4(12)$ \\
\hline
\end{tabular}

Table 3

Specification of the number of fully identified, reported or AST subjected anaerobic isolates per sample.

\begin{tabular}{|c|c|c|c|}
\hline & $\begin{array}{l}\text { Performing full ID } \\
\mathrm{N}=13(100 \%)\end{array}$ & $\begin{array}{l}\text { Reporting full ID } \\
\mathrm{N}=14(100 \%)\end{array}$ & $\begin{array}{l}\text { Performing AST } \\
\mathrm{N}=10(100 \%)\end{array}$ \\
\hline 1 anaerobic isolate & $13(100)$ & $14(100)$ & $10(100)$ \\
\hline 2 anaerobic isolates & $13(100)$ & $14(100)$ & $9(90)$ \\
\hline 3 anaerobic isolates & $4(31)$ & $4(28)$ & $3(30)$ \\
\hline 4 anaerobic isolates & $2(15)$ & $0(-)$ & $0(-)$ \\
\hline 5 anaerobic isolates & $0(-)$ & $1(7)$ & $0(-)$ \\
\hline Unlimited & $1(8)$ & $0(-)$ & $0(-)$ \\
\hline
\end{tabular}

\section{Discussion}

\subsection{Which samples are accepted/rejected for culture of anaerobic bacteria?}

First of all, only samples from body sites where anaerobes are considered as potential pathogens should be accepted for anaerobic culture. Anaerobic culture requested on samples mentioned in Table 5 should not be performed since these samples harbor non-relevant, endogenous colonizing anaerobic bacteria (Garcia \& Hall, 2010). Using current identification methods it is impossible to distinguish colonizing from infectious anaerobic bacteria in irrelevant or poor quality samples.

Secondly, samples should be collected in an appropriate recipient. Aspirates collected with needle and syringe, surgically obtained tissues and biopsies are considered as most suitable specimens for the culture of anaerobic bacteria. Only if no suitable sample type can be obtained (e.g. animal bite wounds involving a small puncture and abscess), swabs can be accepted. Swabs absorb small sample volumes and many organisms tend to adhere to the fibers, reducing the probability that pathogenic and relevant anaerobic species are cultured (Clinical and Laboratory Standards Institute, 2014; Garcia \& Hall, 2010; Jousimies-Somer et al., 2002). Furthermore, swabbing wounds, ulcers or mucous membranes increases the recovery of non-relevant normal microbiota (Dowd et al., 2008a,2008b; Garcia \& Hall, 2010; Jousimies-Somer et al., 2002; Kessler et al., 2006). Inappropriate but irreplaceable specimens (e.g. swabs taken during surgery or from fully drained abscesses) should be processed with a comment on the laboratory

Table 4

Specification of anaerobic species which are always reported or tested for susceptibility.

\begin{tabular}{|c|c|c|}
\hline & $\begin{array}{l}\text { Which strictly anaerobic } \\
\text { species would you } \\
\text { always report to the } \\
\text { clinician? } \mathrm{N}=14(100 \%)\end{array}$ & $\begin{array}{l}\text { From which strictly } \\
\text { anaerobic species } \\
\text { would youalways } \\
\text { test susceptibility? } \\
\mathrm{N}=13(100 \%)\end{array}$ \\
\hline Gram-positive cocci & $2(14)$ & $0(-)$ \\
\hline Propionobacterium spp. & $9(64)$ & $4(31)$ \\
\hline Bacteroides non-fragilis group & $10(71)$ & $9(69)$ \\
\hline Prevotella spp. ${ }^{\mathrm{a}}$ & $10(71)$ & $7(54)$ \\
\hline Actinomyces species & $11(79)$ & $5(38)$ \\
\hline Fusobacterium spp. ${ }^{\mathrm{b}}$ & $11(79)$ & 9 (69) \\
\hline Bacteroides fragilis group & $12(86)$ & $11(85)$ \\
\hline Clostridium spp. ${ }^{\mathrm{c}}$ & $12(86)$ & $6(46)$ \\
\hline
\end{tabular}

${ }^{a}$ P. disiens, P. bivia, P. dentalis, P. melaninogenica; ${ }^{\mathrm{b}}$ F. necrophorum, F. nucleatum,

F. mortiferum, F. avium; ' $C$. histolyticum, C. novyii, C. perfringens, C. septicum, C. sordelii, C. tertium, C. botulinum, C. tetani. report, warning of incorrect collection or transportation (Clinical and Laboratory Standards Institute, 2014; Rosenblatt, 1997).

Survey results revealed that most laboratories are aware of these guideline as they all accepted blood, deep wound aspirates/biopsies and sterile fluids (pleural, ascites and abdominal) for anaerobic culture. Only a minority $(\leq 10 \%)$ would reject sinus aspirates, deep wound swabs, joint fluids and cerebrospinal fluids for culture of anaerobes. Most laboratories ( $\geq 50 \%$ ) correctly rejected bronchial aspirates, sputum, nasopharyngeal swabs, urine, vaginal and cervical swabs, catheter tips and superficial wound swabs for anaerobic culture.

\subsection{Does your laboratory use specific anaerobic collection or transport media?}

In this survey only a few laboratories used specific collection or transport media for anaerobic samples. Laboratories not using specific media should be aware of conditions increasing oxygen exposure and shortening maximum transportation time of anaerobic samples (Imlay, 2002; Thomas \& Eleazer, 2003). Sample volume, recipient and type determine the maximum transportation time (Garcia \& Hall, 2010). Anaerobic bacteria survive for 2-3 hours in large aspirated volumes $(>2 \mathrm{~mL}$, transported in a closed syringe) and in large lumps of tissue (transported in a nonspecific sterile container). Anaerobic bacteria survive only for one hour in dry swabs, small aspirated volumes or small lumps of tissue (Garcia \& Hall, 2010). Although not recognized as a specific transport medium for anaerobic culture samples in official guidelines (Garcia \& Hall, 2010; Jousimies-Somer et al., 2002), there is sufficient evidence that liquid Amies medium is suitable for short-term (4-6 hours) transportation of material containing anaerobic bacteria (Citron et al., 2000; Morosini et al., 2006; Van Horn et al., 1998, 1999, 2008). Fastidious bacteria and low numbers of anaerobic bacteria might be missed after longer storage and transport of swabs in liquid Amies medium (Citron et al., 2000; Morosini et al., 2006; Van Horn et al., 2008). All samples in specific anaerobic transport media can be accepted for anaerobic culture with reliable results even after a delay of 8-24 h (Clinical and Laboratory Standards Institute, 2012). If clinicians insist on culturing samples with exceeded transportation time, a comment should be included regarding transport delay on the final culture report (Clinical and Laboratory Standards Institute, 2012). All laboratories should introduce rejection criteria based on maximum transportation time. Since it is difficult to monitor time between sampling and delivery in the laboratory, only a few laboratories use rejection criteria based on transportation time (Fig. A.1). 


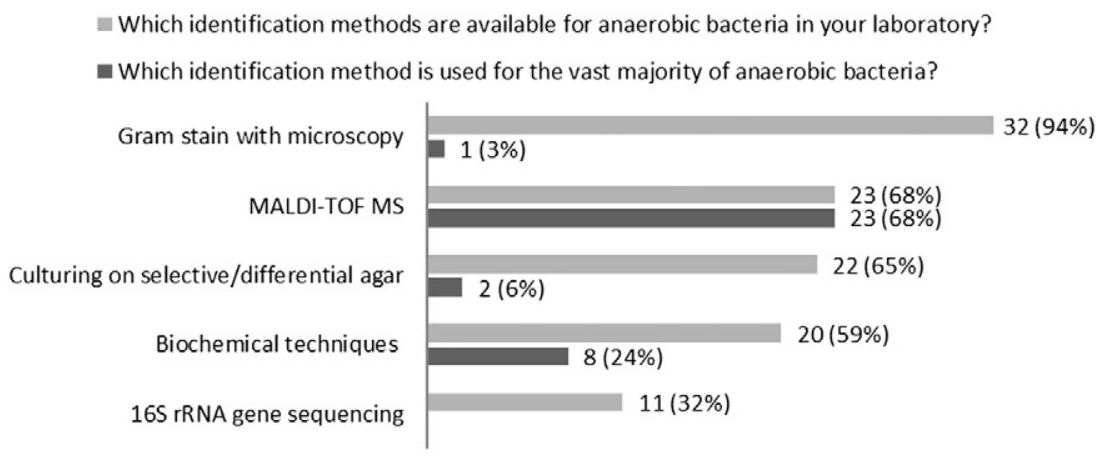

Fig. 1. Overview of available and most used identification methods for anaerobic bacteria. $\mathrm{N}=34$ (100\%).

\subsection{What is the current rationale in your laboratory for identifying,} reporting and AST of anaerobic bacteria?

The rationale for identification, reporting and AST of anaerobic bacteria varied between the participating laboratories. Some guidelines and articles suggested a limited identification policy for anaerobes based on either the clinical context or the number of different isolated anaerobic bacteria. We are not aware of guidelines regarding reporting strategies of anaerobic culture results, so we considered all strategies mentioned in our survey as expert-based.

Anaerobic cultures from serious infections such as central nervous system, ocular, serious pulmonary or soft tissue infections, liver abscesses, osteomyelitis, and infections in any normally sterile body site require a complete workup, independent of the number of different cultivated bacteria (Citron \& Appelbaum, 1993). According to Cumitech guidelines the identification extent depends on the clinical situation. More specifically, bacteremia, tubo-ovarian and lung abscesses, serious skin, soft tissue, bone and joint infections and every infection not responding to antimicrobial therapy require full identification of all anaerobic colony types (Rodloff et al., 1991). If only strict anaerobic bacteria are grown from clinical samples, a complete identification is warranted (Citron \& Appelbaum, 1993; Clinical and Laboratory Standards Institute, 2014; Garcia \& Hall, 2010; Jousimies-Somer et al., 2002). In accordance with guidelines and literature, sample origin seemed to be the most important element for identifying and reporting anaerobic bacteria in this survey. Most laboratories mentioned that a more extensive work-up is used if samples originated from normally sterile body sites.

If a mixed aerobic/anaerobic flora is likely to cause the infection, some claim full identification is not necessary (Citron \& Appelbaum, 1993; Garcia \& Hall, 2010; Van Horn et al., 2008) and the extent of isolation and identification should depend on the diversity of growth. If five or more anaerobic colony types appear to be present (including facultative organisms), no clinical benefit in identifying individual isolates exists and mixed flora may be reported (Rosenblatt, 1997). Although no guideline supports this rationale, thirteen and fourteen questioned laboratories were restrictive in identifying and reporting more than two strictly anaerobic isolates, respectively. This approach may overlook the fact that all organisms grown from a relevant and qualitative specimen may be involved in the infection and some can be resistant to anti-microbial agents. Because many anaerobic infections from non-sterile sites are poly-microbial and bacterial constituents

\footnotetext{
Table 5

Samples types and body sites always harboring endogenous colonizing anaerobic bacteria (Clinical and Laboratory Standards Institute, 2012).

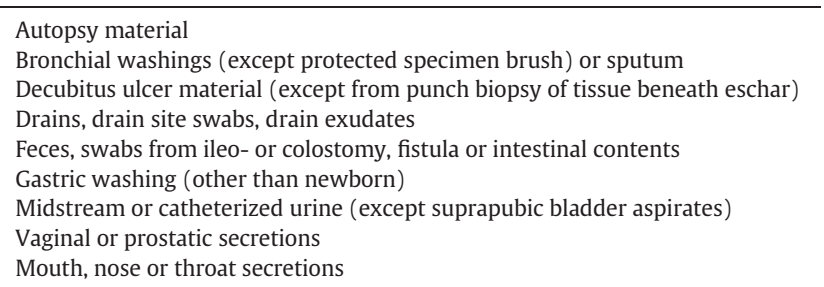

may act synergistically, identification of all colony types is advised by some experts (Clinical and Laboratory Standards Institute, 2014).

Fourteen questioned clinical microbiologists were guided by identified anaerobic genus or species in reporting or performing AST. They recognized the difference in virulence and resistance patterns of anaerobic bacteria. Gram-negative anaerobic bacteria, especially Bacteroides fragilis group and histotoxic Clostridium spp. were most often reported and tested for susceptibility. We concluded that the aspect of virulence and potential antimicrobial resistance should be incorporated in our clinically orientated and evidence-based workup scheme.

After an extensive literature review only three reasons were found, justifying isolation, identification and reportage of anaerobic bacteria. Reported and fully identified anaerobic bacteria can give information about the primary site of infection (Section 4.3.1), they can exhibit exceptional virulence (Section 4.3.2) or they can already predict possible anti-microbial resistance (Section 4.3.3).

\subsubsection{Which anaerobic bacteria give information about the primary site of infection?}

There are few specific clinical conditions or syndromes caused by anaerobic bacteria. Clostridium difficile associated colitis is always caused by Clostridium difficile, which can be detected from faeces (Clinical and Laboratory Standards Institute, 2014; Garcia \& Hall, 2010; Jousimies-Somer et al., 2002). Actinomycosis can be caused by several Actinomyces spp., isolated from tissue/biopsy or aspirated pus. The isolation and identification of Actinomyces spp. from mucosa, where these bacteria are normal inhabitants, is of no clinical significance in most cases. Exceptions are the presence of sulfur granules or a typical clinical syndrome, highlighting the importance of relevant clinical information and a correct interpretation of microbiological investigations in combination with histological analysis (Garcia \& Hall, 2010; Valour et al., 2014). Spontaneous or traumatic clostridial myonecrosis is caused by histotoxic Clostridium spp. such as Clostridium perfringens, Clostridium histolyticum, Clostridium novyi, Clostridium septicum, Clostridium fallax, Clostridium bifermentas, or Clostridium sordellii. Diagnosis can be made by the isolation of these bacteria from tissue samples (Brook, 2008; Garcia \& Hall, 2010; Rodloff et al., 1991). In Lemierre syndrome Fusobacterium necrophorum is the most prevalent etiological bacteria. Other causative Fusobacteria include Fusobacterium nucleatum, Fusobacterium gonidiaformans and Fusobacterium varium. (Garcia \& Hall, 2010; Karkos et al., 2009). Samples for Lemierre syndrome diagnosis are blood cultures and aspirates from peritonsillar abscesses. Tetanus is caused by Clostridium tetani, and although the bacteria can sometimes be cultured from wound tissue or aspirates, the diagnosis is mainly based upon clinical presentation (Clinical and Laboratory Standards Institute, 2014; Garcia \& Hall, 2010; Jousimies-Somer et al., 2002). Isolation of Clostridium botulinum and detection of toxins from faeces, wound tissue or aspirates or suspected food is necessary for a definitive diagnosis of botulism but is mostly performed in specialized reference laboratories (Clinical and Laboratory Standards Institute, 2014; Garcia \& Hall, 2010; Jousimies-Somer et al., 2002).

In nearly all cases, detection of any anaerobic bacteria from sterile body fluids (blood, cerebrospinal, pleural, ascites, joint fluid) can be 
Table 6

Virulence factors of anaerobic bacteria.

\begin{tabular}{|c|c|c|c|}
\hline $\begin{array}{l}\text { Clinical important } \\
\text { virulence factors }\end{array}$ & Effect, mechanism & Relevant for & Reference \\
\hline Pili, lectin, fimbria & Adherence, colonization & $\begin{array}{l}\text { B. fragilis, } P \text {. melaninogenica, } F \text {. nucleatum, } \\
\text { P. gingivalis, F. magna }\end{array}$ & (Versalovic et al., 2011; Hofstad, 1992) \\
\hline Superoxide dismutase & Aero-tolerance & Most anaerobic bacteria & (Versalovic et al., 2011; Hofstad, 1992) \\
\hline $\begin{array}{l}\text { Hyaluronidase, collagenase, } \\
\text { fibrinolysis }\end{array}$ & Invasion of tissue & $\begin{array}{l}\text { F. magna and other Gram-positive cocci, } \\
\text { anaerobic Gram-negative bacilli, } \\
\text { Clostridium spp. }\end{array}$ & (Versalovic et al., 2011; Hofstad, 1992) \\
\hline Immunoglobulin proteases & $\begin{array}{l}\text { Evasion or inactivation } \\
\text { of cellular or humoral } \\
\text { immunity }\end{array}$ & B. fragilis and other anaerobic Gram-negative bacteria & (Hofstad, 1992) \\
\hline $\begin{array}{l}\text { Mutual enhancement } \\
\text { of growth }\end{array}$ & $\begin{array}{l}\text { Synergy } \\
\text { (mechanism unclear) }\end{array}$ & $\begin{array}{l}\text { Especially } P \text {. aeruginosa or } S \text {. aureus with anaerobic cocci or } \\
\text { Gram-negative bacilli }\end{array}$ & (Brook et al., 1984) \\
\hline Capsule formation & $\begin{array}{l}\text { Higher virulence } \\
\text { (mechanism unclear) }\end{array}$ & $\begin{array}{l}\text { Bacteroides spp., Prevotella spp., Porphyromonas spp., } \\
\text { Fusobacterium spp., } \\
\text { Clostridium spp., F. magna and other anaerobic } \\
\text { Gram-positive cocci }\end{array}$ & (Brook \& Walker, 1983) \\
\hline Toxins & Neuro-, histo- or cytotoxic & Various Clostridium spp. & (Versalovic et al., 2011; Rodloff et al., 1991) \\
\hline
\end{tabular}

interpreted as diagnostic for an infection of this body site and all isolates should be reported with full identification (Citron \& Appelbaum, 1993; Clinical and Laboratory Standards Institute, 2014).

Sometimes, the isolation of specific anaerobic bacteria can be indicative of underlying medical problems. For example, presence of a lung abscess can be indicative for an underlying bronchogenic malignancy (Pohlson et al., 1985), a sepsis with Clostridium spp. (especially Clostridium septicum) can be associated with colon malignancy (Rechner et al., 2001) and bacteremia with Gram-negative anaerobic bacilli is common in patients with solid tumors of the gastro-intestinal or urogenital tract. Felner and Dowell reported that $23 \%$ of patients with Bacteroides fragilis group, Fusobacterium spp. or Prevotella spp. bacteremia had a malignancy as a predisposing factor (e.g. adenocarcinoma of the colon, uterine or cervical tumors) (Felner, 1971). A brain abscess can develop due to an underlying dental infection (Schuman \& Turner, 1994). Overall the gastrointestinal tract (49\%), female genital tract (20\%), throat (11\%), skin and soft tissue (9\%) and lower respiratory tract (6\%) are described as the main anatomic foci of anaerobic bacteremia (Goldstein, 1996).

Isolated anaerobic bacteria are often a reflection of the endogenous flora near the infectious site, especially if there still is an anatomical connection but also for secluded abscesses (Brook, 2002). From skin and subcutaneous wounds and abscesses one can expect to isolate Bacteroides fragilis group (rectal area), Prevotella spp. and Porphyromonas spp. (oral area). Deep head and neck abscesses mainly harvest Prevotella spp., Porphyromonas spp., Fusobacterium spp. and Gram-positive cocci (especially Finegoldia magna, Parvimonas micra and Peptoniphilus harei). From abdominal abscesses Bacteroides fragilis group, Clostridium spp. and Gram-positive cocci are the most frequent isolates anaerobic bacteria while in pelvic abscesses Prevotella spp. and Bacteroides spp. are the dominant genera (Brook, 2002, 2008).

\subsubsection{Which anaerobic bacteria have exceptional virulence?}

The major virulence factors of anaerobes are summarized in Table 6. For anaerobic Gram-negative bacilli, two studies tried to extrapolate mice model findings to human infections (Brook, 1986; Brook \& Gober, 1983; Brook et al., 1992). Conclusions of these studied highlighted the importance of encapsulated anaerobic organisms in acute and chronic infections.

The pathogenicity of anaerobic cocci in human infections is not clear. Although most infections involving anaerobic cocci are poly-microbial, there are several reports of infections with just one species (e.g. Finegoldia magna, Peptostreptococcus anaerobius, Peptoniphilus asaccharolyticus, Peptoniphilus harei, Peptoniphilus indolicus, Parvimonas micra, Anaerococcus vaginalis) which may suggest some are more virulent then others. Finegoldia magna is considered as the most virulent among Gram-positive cocci and is frequently isolated in pure culture from various infections (Garcia \& Hall, 2010). Anaerobic Gramnegative cocci rarely seem to cause infections (Versalovic et al., 2011).

Virulence factors and human pathogenicity of non-sporulating Grampositive bacilli are not studied thoroughly. Non-sporulating Gram-positive bacilli are usually isolated as part of a poly-microbial flora from many different infections. Only for some Actinomyces spp. (Actinomyces israelli, Actinomyces gerencseriae and Actinomyces graevenitzii), isolated in pure culture from proven actinomycosis, evidence about virulence exists (Versalovic et al., 2011).

4.3.3. Which anaerobic bacteria can be resistant to anti-microbial agents?

Periodic monitoring of regional and institutional resistance trends of clinically relevant anaerobic bacteria is recommended, to guide empirical therapy (Clinical and Laboratory Standards Institute, 2012). Wybo et al. recently published the fourth Belgian multicenter survey of antibiotic susceptibility of anaerobic bacteria (Wybo et al., 2014). This survey concludes that resistance is observed in all anaerobic species but especially in Bacteroides spp. and Parabacteroides spp. Amoxicillin-clavulanic acid, piperacillin-tazobactam, meropenem and metronidazole maintain a good activity against most anaerobes and remain suitable for empirical use. Anaerobic bacteria show increasing resistance to penicillin, clindamycin and moxifloxacin thus empirical use of these agents should be discouraged.

Four indications for anaerobic AST are suggested by CLSI guidelines (Clinical and Laboratory Standards Institute, 2012, 2015). Firstly there might be an elevated resistance rate of particular organisms for certain antibiotics. In Belgium Bacteroides fragilis and Bacteroides non-fragilis group should be tested because of unpredictable susceptibility (Boyanova et al., 2015; Wybo et al., 2014). Secondly, persistent infection despite adequate treatment with an appropriate therapeutic regimen is a reason for AST. This strategy does not seem necessary for clinical laboratories, since all clinical isolates should be stored anaerobically for possible future AST. In case of persistent infection, clinicians should collect new qualitative samples for isolation, identification and AST of anaerobes. Thirdly, AST can be performed to assess empirical antibiotic therapy. Finally, infections requiring long-term therapy like brain abscesses, endocarditis, osteomyelitis, joint infection, infections of prosthetic devices, vascular grafts and bacteremia demand AST of all anaerobic isolates. Anaerobic isolates from normally sterile body sites should be tested unless they are believed to be contaminants. Brook et al. and Schuetz et al. also recommend AST of anaerobic pure cultures and all highly virulent strains like Prevotella spp., Fusobacterium spp., Clostridium spp., Bilophila wadsworthensis and Sutterella wadsworthensis (Brook et al., 2013).

\subsection{Which identification method is used for anaerobic bacteria?}

MALDI-TOF MS is proven to be accurate and utile for routine identification of many anaerobic bacteria (Barba et al., 2014; Biswas \& Rolain, 2013; Citron, 2012; Croxatto et al., 2012; Hsu \& Burnham, 2014; Patel, 2015). Obviously, quality and size of the identification database will influence the performance of MALDI-TOF MS-based identifications. A review by Biswas et al. demonstrated the accuracy of MALDI-TOF MS-based identification of bacteria that are difficult to culture, including many anaerobic bacteria (Biswas \& Rolain, 2013). 
MALDI-TOF MS clearly is the method of choice for routine identification of anaerobic isolates in most questioned laboratories. There were no labs using $16 \mathrm{~S}$ rRNA gene sequencing as routine identification method. Possibly, this complex method is difficult to implement in identification and work-up schemes. Gram staining remains a cornerstone in presumptive identification of anaerobic bacteria. Diverse selective/differential agars and biochemical techniques were available in laboratories but were not used for routine identification.

\subsection{Towards a clinically orientated and feasible workup for anaerobes}

Based upon discussed literature and guidelines, we present a clinical and evidence-based workup scheme using MALDI-TOF MS identification for anaerobes (Fig. 2). Guarding sample quality and relevance remains fundamental even if advanced identification methods like MALDI-TOF MS are used. Inadequate samples give rise to incorrect and misleading anaerobic culturing results, potentially leading to inefficient therapy. However, there are no studies evaluating the clinical impact of incorrect anaerobic culture results. A limited workup based on the diversity of aerobic and/or anaerobic colony types seems no longer justified when identification by MALDI-TOF MS is available and all colony types suspicious for being strictly anaerobic bacteria should be identified. The rationale for reporting anaerobic isolates is threefold. Firstly all isolated and identified anaerobic bacteria from serious infections should be reported. Secondly, pathognomonic anaerobic bacteria should be reported from typical anaerobic syndromes. Finally, if the sample does not originate from a serious infection or a typical anaerobic syndrome, only highly virulent anaerobes with(out) unpredictable susceptibility should be reported. In this case, all other anaerobic isolates can be reported as low-virulent anaerobic flora with predictable susceptibility. AST should be performed of all reported anaerobic species from serious infections or typical anaerobic syndromes. In all other cases AST should only be performed from anaerobic Gram-negative bacilli and anaerobes isolated in pure culture. If no AST is performed, anti-microbial therapy should be based on local resistance data and epidemiology of anaerobes. However, this information is not always available when guidelines for anaerobic culturing and AST are not followed by national or local authorities (Goldstein et al., 1992, 2008). Implementation of a uniform and evidence-based workup scheme for anaerobic cultures could result in a more efficient and clinical relevant microbiology. However, the real clinical impact should be the subject of further research. The suggested scheme only highlights the foundations of a proper workup and should be customized for each laboratory, considering technical expertise, available resources, budget constraints, and clinical needs. Workup schemes should also be updated if there is new evidence of virulence or resistance in certain anaerobic species. Although MALDI-TOF MS identification is centralized in our workup scheme, laboratories can use Fig. 2 as a general procedure, using other identification methods for anaerobic bacteria.

\section{Conclusions}

Currently there is no consensus regarding anaerobic microbiology practices in Belgium. In this laboratory survey, we observed different identification and reporting strategies for anaerobic bacteria. Whether or not colony types were identified was mainly based on anatomical origin of the sample, colony morphology and total number of different anaerobic isolates in the sample, while reporting of isolate results and performance of AST mainly was based on anatomical origin of the sample, number of different anaerobic isolates and the identification of the anaerobic bacteria. Organizations like the ESCMID Study Group for Anaerobic Infections are trying to harmonize European practices in anaerobic microbiology, centralizing MALDI-TOF MS-based bacterial identifications in their workup schemes.

\section{Transparency declaration}

The authors declare no conflicts of interest.

\section{Acknowledgments}

We would like to thank all participating laboratories: AZ Sint-Lucas Gent, AZ Sint-Maarten Mechelen, GZA Antwerpen, AZ Diest, AZ Sint-Jozef

A clinically orientated procedure for the workup of anaerobic bacteria using MALDI-TOF MS.

\begin{tabular}{|c|c|c|c|}
\hline \multicolumn{4}{|c|}{ A clinically orientated procedure for the workup of anaerobic bacteria using MALDI-TOF MS. } \\
\hline $\begin{array}{c}\text { Rejection or acceptance } \\
\text { of samples for } \\
\text { anaerobic culture? }\end{array}$ & \multicolumn{3}{|c|}{ 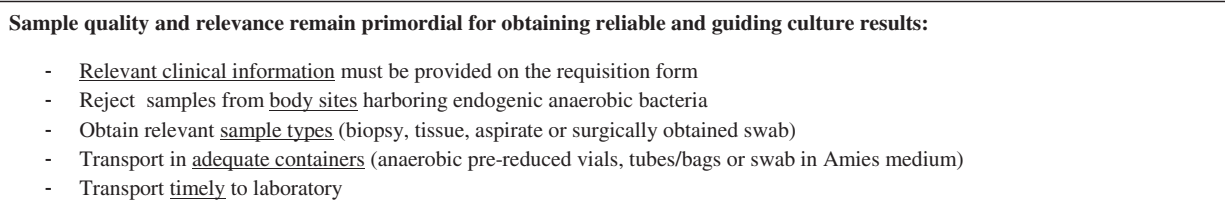 } \\
\hline $\begin{array}{l}\text { When to identify } \\
\text { anaerobic colony }\end{array}$ & \multicolumn{3}{|c|}{$\begin{array}{l}\text { Identify all anaerobic colony types, strongly suspicious for being a strictly anaerobic bacteria: compare morphology of aerobic and } \\
\text { anaerobic growth, typical odor, look out for typical anaerobic colony morphology. }\end{array}$} \\
\hline \multirow{3}{*}{$\begin{array}{l}\text { Rationale for reporting } \\
\text { fully identified } \\
\text { anaerobic bacteria? }\end{array}$} & $\begin{array}{l}\text { Serious infection involving anaerobic } \\
\text { bacteria? }\end{array}$ & $\begin{array}{l}\text { Typical anaerobic clinical } \\
\text { syndrome? }\end{array}$ & $\begin{array}{l}\text { Not a typical anaerobic clinical syndrome? } \\
\text { No serious infection? }\end{array}$ \\
\hline & \multirow[t]{2}{*}{$\begin{array}{ll}\text { Report } \frac{\text { ALL anaerobic organisms to }}{\text { species level: }} \\
\text { - } & \text { Central nervous system infection } \\
\text { - } & \text { Sterile body site infection (ascites, } \\
& \text { pleural fluid, bloodstream) } \\
\text { - } & \text { Tubo-ovarian infection } \\
\text { - } & \text { Liver infection } \\
\text { - } & \text { Joint or graft infection } \\
\text { - } & \text { Ocular infection } \\
\text { - } & \text { Endocarditis } \\
\text { - } & \text { Osteomyelitis }\end{array}$} & \multirow{2}{*}{ 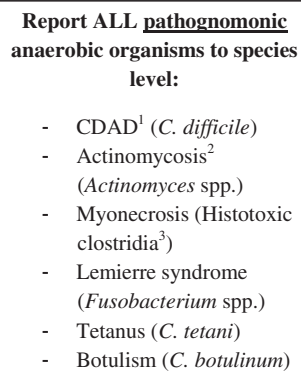 } & 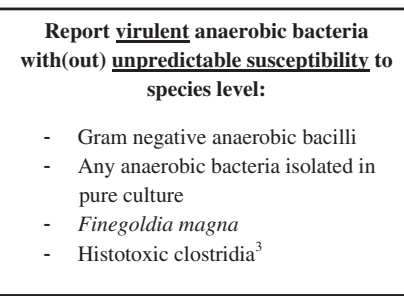 \\
\hline & & & $\begin{array}{l}\text { Report other anaerobic bacteria simply as } \\
\text { "Other low-virulent anaerobic flora with } \\
\text { predictable susceptibility present" }\end{array}$ \\
\hline $\begin{array}{l}\text { When to perform } \\
\text { anaerobic AST? }\end{array}$ & \multicolumn{2}{|c|}{ Perform AST of ALL anaerobic species } & $\begin{array}{l}\text { Perform AST of anaerobic Gram negative } \\
\text { bacilli and bacteria isolated in pure culture }\end{array}$ \\
\hline
\end{tabular}

Fig. 2. Clinically orientated procedure for the workup of anaerobic bacteria using MALDI-TOF MS identification. 
Malle, Ziekenhuis Maas en Kempen Maaseik, OLV van Lourdes Ziekenhuis Waregem, Sint-Andries Ziekenhuis Tielt, AZ Herentals, AZ Klina Brasschaat, MCH Leuven, CHU Saint-Pierre Bruxelles, AZ Vesalius Tongeren, UZ Gent, AZ Delta Roeselare-Menen, AZ Nikolaas Sint-Niklaas, AZ Sint-Jan Brugge, ZOL Genk, UZ Gasthuisberg Leuven, AZ Heilige Familie Reet, ZNA Middelheim Antwerpen, AZ Sint-Dimpna Geel, Hôpital Erasme Bruxelles, Heilig Hartziekenhuis Lier, OLV Ziekenhuis Aalst, UZA Antwerpen, UZ Brussel, JYZ Ieper, AZ Sint-Blasius Zele, AZ Alma Eeklo, AZ Sint-Augustinus Veurne, AZ Jan Portaels Vilvoorde, AZ Turnhout, Jessa Ziekenhuis Hasselt.

\section{Appendix A. Appendices}

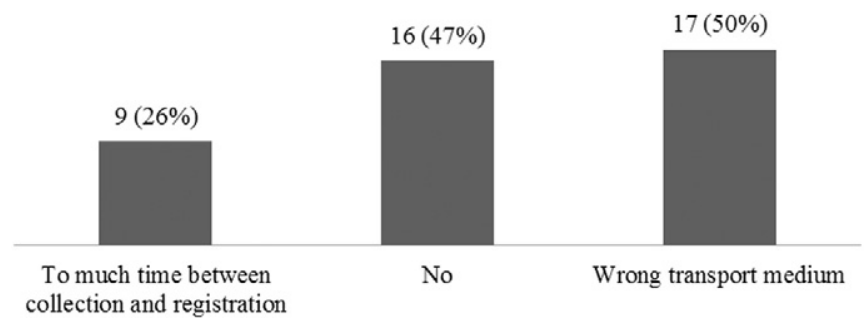

Fig. A.1. Do you use other rejection criteria besides sample type for performing anaerobic culture? $\mathrm{N}=34(100 \%)$

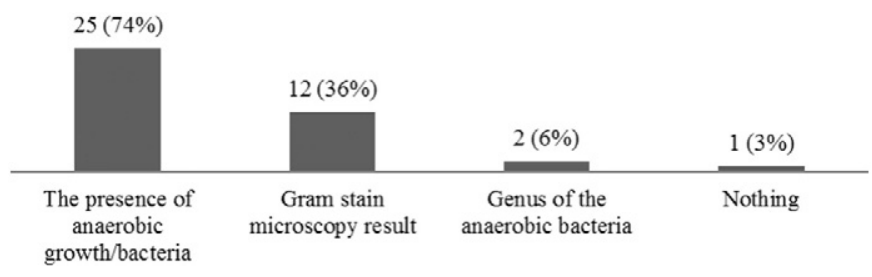

Fig. A.2. What is reported to the clinician if a limited workup of an anaerobic culture is applied? $\mathrm{N}=34(100 \%)$

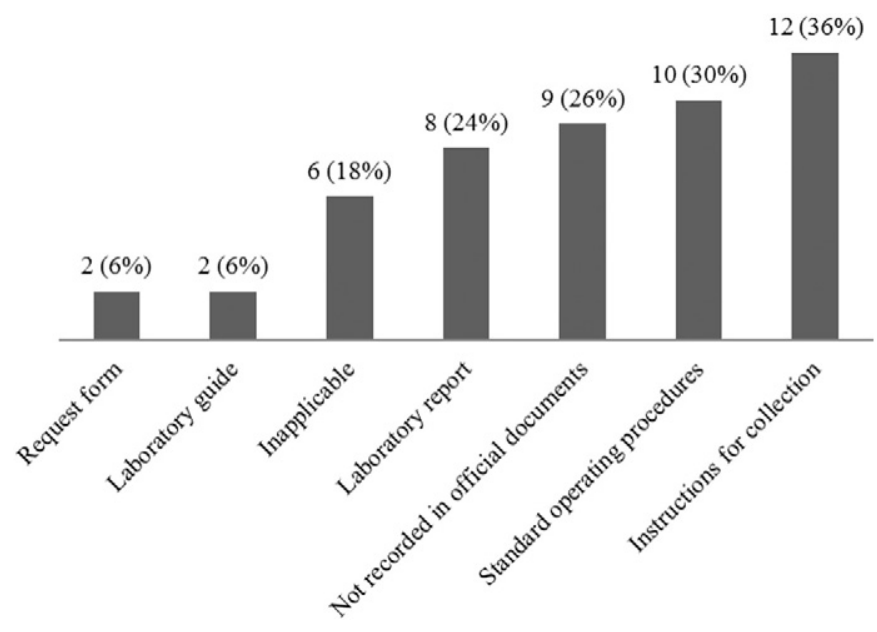

Fig. A.3. In which documents do you mention rejection criteria for anaerobic culture? $\mathrm{N}=34$ (100\%).

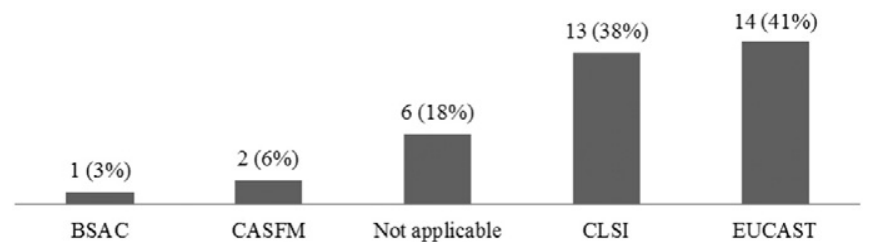

Fig. A.4. Which breakpoints do you use for the interpretation of anaerobic susceptibility testing? N = 34 (100\%). BSAC: British Society for Antimicrobial Chemotherapy; CASFM: Comité de l'Antibiogramme de la Société Française de Microbiologie; CLSI: Clinical and Laboratory Standards Institute; EUCAST: European Committee on Antimicrobial Susceptibility Testing.

Table A.2

Which anti-microbial agents do you test for anaerobic bacteria?

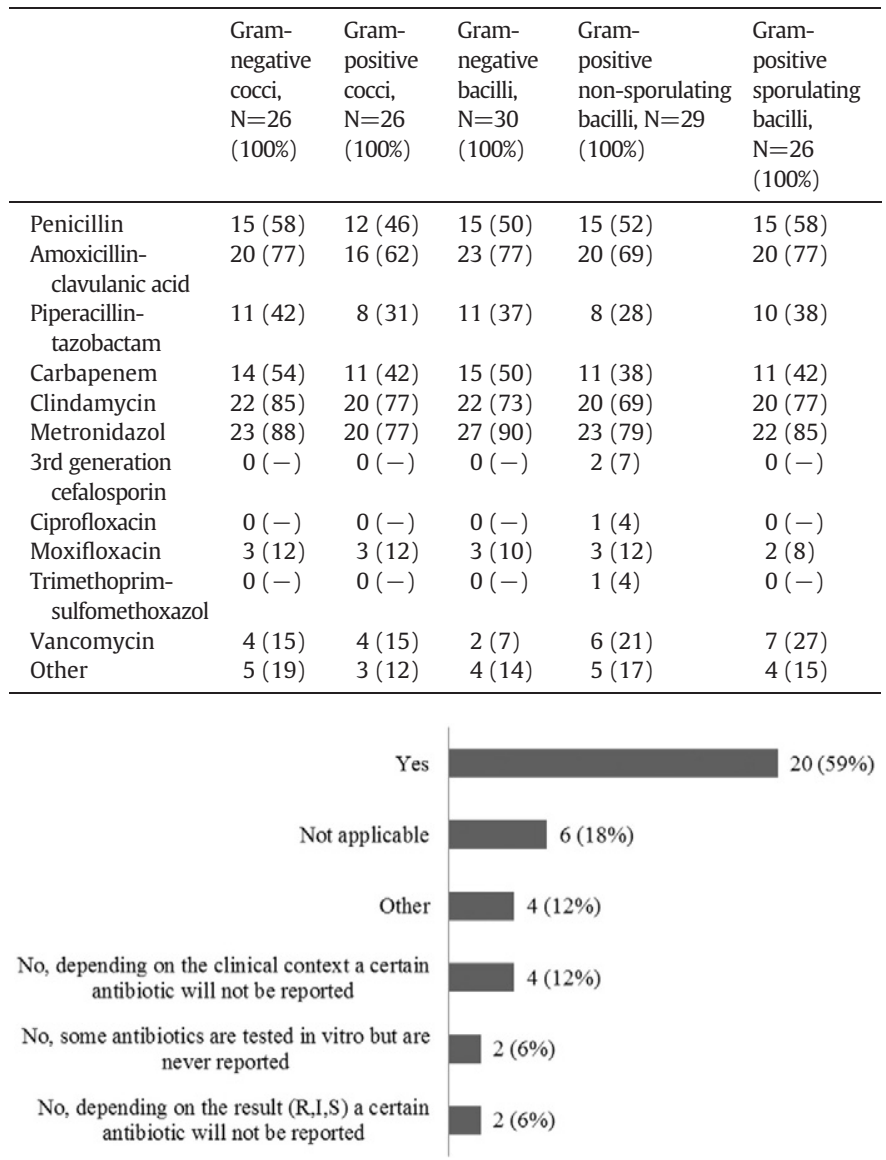

Fig. A.5. Do you use non-selective reporting for tested anti-microbial agents? $\mathrm{N}=34$ (100\%).

\section{References}

Barba MJ, Fernández A, Oviaño M, Fernández B, Velasco D, Bou G. Evaluation of MALDI-TOF mass spectrometry for identification of anaerobic bacteria. Anaerobe 2014;30C:126-8.

Table A.1

How do you perform susceptibility testing for strictly anaerobic bacteria?

\begin{tabular}{|c|c|c|c|c|c|}
\hline $\mathrm{N}=34(100 \%)$ & Gram-negative cocci & Gram-positive cocci & Gram-negative bacilli & Gram-positive non-sporulating bacilli & Gram-positive sporulating bacilli \\
\hline Not performed for this group & $8(24)$ & $8(24)$ & $4(17)$ & $5(15)$ & $8(24)$ \\
\hline \multicolumn{6}{|c|}{ On which agar do you perform susceptibility testing for strictly anaerobic bacteria? } \\
\hline Brucella blood & $6(18)$ & $6(18)$ & $7(21)$ & $7(21)$ & $7(21)$ \\
\hline Mueller-Hinton-5\% blood & $7(21)$ & $7(21)$ & $8(24)$ & $8(24)$ & $8(24)$ \\
\hline Schaedler & $9(26)$ & $9(26)$ & $11(32)$ & $10(29)$ & $6(18)$ \\
\hline Other & $4(17)$ & $4(17)$ & $4(17)$ & $4(17)$ & $5(15)$ \\
\hline \multicolumn{6}{|c|}{ Which method is used for testing susceptibility of strictly anaerobic bacteria? } \\
\hline E-test & $11(32)$ & $11(32)$ & $12(35)$ & $14(41)$ & $13(38)$ \\
\hline Disk diffusion test & $12(35)$ & $12(35)$ & $14(41)$ & $12(35)$ & $10(29)$ \\
\hline Other & $3(9)$ & $3(9)$ & $3(9)$ & $3(9)$ & $3(9)$ \\
\hline
\end{tabular}


Biswas S, Rolain JM. Use of MALDI-TOF mass spectrometry for identification of bacteria that are difficult to culture. J Microbiol Methods 2013:92(1):14-24

Boyanova L, Kolarov R, Mitov I. Recent evolution of antibiotic resistance in the anaerobes as compared to previous decades. Anaerobe 2015;31:4-10.

Brook I. Isolation of capsulate anaerobic bacteria from orofacial abscesses. J Med Microbiol 1986;22(2):171-4.

Brook I. Microbiology of polymicrobial abscesses and implications for therapy. J Antimicrob Chemother 2002;50(6):805-10.

Brook I. Microbiology and management of soft tissue and muscle infections. Int J Surg 2008;6(4):328-38.

Brook I, Gober AE. Bacteroides melaninogenicus. Its recovery from tonsils of children with acute tonsillitis. Arch Otolaryngol 1983:109(12):818-20.

Brook I, Walker RI. Infectivity of organisms recovered from polymicrobial abscesses. Infect Immun 1983;42(3):986-9.

Brook I, Hunter V, Walker RI. Synergistic effect of bacteroides, Clostridium, Fusobacterium, anaerobic cocci, and aerobic bacteria on mortality and induction of subcutaneous abscesses in mice. J Infect Dis 1984;149(6):924-8.

Brook I, Myhal LA, Dorsey CH. Encapsulation and pilus formation of Bacteroides spp. in normal flora abscesses and blood. J Infect 1992;25(3):251-7.

Brook I, Wexler HM, Goldstein EJ. Antianaerobic antimicrobials: spectrum and susceptibility testing. Clin Microbiol Rev 2013;26(3):526-46.

Citron DM. Pre-molecular identification: ignorance was bliss? Anaerobe 2012;18(2): 189-91.

Citron DM, Appelbaum PC. How far should a clinical laboratory go in identifying anaerobic isolates, and who should pay? Clin Infect Dis 1993;16(Suppl. 4):S435-8.

Citron DM, Warren YA, Hudspeth MK, Goldstein EJ. Survival of aerobic and anaerobic bacteria in purulent clinical specimens maintained in the Copan Venturi Transystem and Becton Dickinson Port-a-Cul transport systems. J Clin Microbiol 2000;38(2):892-4.

Clinical and Laboratory Standards Institute. M11-A8 Methods for Antimicrobial Susceptibility Testing of Anaerobic Bacteria. Approved guideline, Vol. 32 No.5. ; 2012.

Clinical and Laboratory Standards Institute. M56-A Principles and Procedures for Detection of Anaerobes in Clinical Specimens. Approved Guideline, Vol. 34 No.10. ; 2014.

Clinical and Laboratory Standards Institute. M100-S25 Performance Standards for Antimicrobial Susceptibility Testing. Twenty-Fifth Informational Supplement, Vol. 35 No.3. ; 2015.

Croxatto A, Prod'hom G, Greub G. Applications of MALDI-TOF mass spectrometry in clinical diagnostic microbiology. FEMS Microbiol Rev 2012;36(2):380-407.

Dowd SE, Wolcott RD, Sun Y, McKeehan T, Smith E, Rhoads D. Polymicrobial nature of chronic diabetic foot ulcer biofilm infections determined using bacterial tag encoded FLX amplicon pyrosequencing (bTEFAP). PLoS One 2008a;3(10), e3326.

Dowd SE, Sun Y, Secor PR, Rhoads DD, Wolcott BM, James GA, et al. Survey of bacterial diversity in chronic wounds using pyrosequencing, DGGE, and full ribosome shotgun sequencing. BMC Microbiol 2008b;8:43.

Felner JM. Dowell VR: "Bacteroides" bacteremia. Am J Med 1971;50(6):787-96.

Garcia LS, Hall GS. Clinical Microbiology Procedures Handbook - Section 4 Anaerobic Bacteriology. 3 ed. Washington: ASM press; 2010.

Goldstein EJ. Anaerobic bacteremia. Clin Infect Dis 1996;23(Suppl. 1):S97-S101.

Goldstein EJ, Citron DM, Goldman RJ. National hospital survey of anaerobic culture and susceptibility testing methods: results and recommendations for improvement. J Clin Microbiol 1992;30(6):1529-34.
Goldstein EJ, Citron DM, Goldman RJ, Claros MC, Hunt-Gerrado S. United States National Hospital Survey of anaerobic culture and susceptibility methods. II. Anaerobe 1995;1(6):309-14.

Goldstein EJ, Citron DM, Goldman PJ, Goldman RJ. National hospital survey of anaerobic culture and susceptibility methods: III. Anaerobe 2008;14(2):68-72.

Hofstad T. Virulence factors in anaerobic bacteria. Eur J Clin Microbiol Infect Dis 1992; 11(11):1044-8.

Hsu YM, Burnham CA. MALDI-TOF MS identification of anaerobic bacteria: assessment of pre-analytical variables and specimen preparation techniques. Diagn Microbiol Infect Dis 2014;79(2):144-8.

Imlay JA. How oxygen damages microbes: oxygen tolerance and obligate anaerobiosis. Adv Microb Physiol 2002;46:111-53.

Jousimies-Somer HR, Summanen P, Citron DM, Baron EJ, Wexler HM, Finegold SM. Wadsworth-KTL Laboratories: Anaerobic Bacteriology Manual. 6 ed. Belmont: Star Publishing Company; 2002.

Karkos PD, Asrani S, Karkos CD, Leong SC, Theochari EG, Alexopoulou TD, et al. Lemierre's syndrome: A systematic review. Laryngoscope 2009;119(8):1552-9.

Kessler L, Piemont Y, Ortega F, Lesens O, Boeri C, Averous C, et al. Comparison of microbiological results of needle puncture vs. superficial swab in infected diabetic foot ulcer with osteomyelitis. Diabet Med 2006;23(1):99-102.

Morosini MI, Loza E, Gutiérrez O, Almaraz F, Baquero F, Cantón R. Evaluation of 4 swab transport systems for the recovery of ATCC and clinical strains with characterized resistance mechanisms. Diagn Microbiol Infect Dis 2006;56(1):19-24.

Patel R. MALDI-TOF MS for the diagnosis of infectious diseases. Clin Chem 2015;61(1):100-11.

Pohlson EC, McNamara JJ, Char C, Kurata L. Lung abscess: a changing pattern of the disease. Am J Surg 1985;150(1):97-101.

Rechner PM, Agger WA, Mruz K, Cogbill TH. Clinical features of clostridial bacteremia: a review from a rural area. Clin Infect Dis 2001;33(3):349-53.

Rodloff AC, Appelbaum PC, Zabransky RJ. Cumulative Techniques and Procedures in Clinical Microbiology: Cumitech 5A, Practical Anaerobic Microbiology. American Society for Microbiology; 1991.

Rosenblatt JE. Can we afford to do anaerobic cultures and identification? A positive point of view. Clin Infect Dis 1997;25(Suppl. 2):S127-31.

Schuman NJ, Turner JE. Brain abscess and dentistry: a review of the literature. Quintessence Int 1994;25(6):411-3.

Thomas SJ, Eleazer PD. Aerotolerance of an endodontic pathogen. J Endod 2003;29(10):644-5

Valour F, Sénéchal A, Dupieux C, Karsenty J, Lustig S, Breton P, et al. Actinomycosis: etiology, clinical features, diagnosis, treatment, and management. Infect Drug Resist 2014;7:183-97.

Van Horn K, Toth C, Warren K. Comparison of Copan Amies agar swab and BBL- Port-A-Cul swab for recovery of anaerobic bacteria. ASM 98th General Meeting, poster C-437; 1998

Van Horn K, Warren K, Toth C. Comparison of four swab systems for recovery of anaerobic bacteria. ASM 99th General Meeting, poster C-32; 1999.

Van Horn KG, Audette CD, Sebeck D, Tucker KA. Comparison of the Copan ESwab system with two Amies agar swab transport systems for maintenance of microorganism viability. J Clin Microbiol 2008;46(5):1655-8.

Versalovic J, Caroll KC, Funke G, Jorgensen JH, Landry ML, Warnock DW. Manual of Clinical Microbiology. 10 ed. Washington: ASM press; 2011.

Wybo I, Van den Bossche D, Soetens O, Vekens E, Vandoorslaer K. Claeys G, et al. Fourth Belgian multicentre survey of antibiotic susceptibility of anaerobic bacteria. J Antimicrob Chemother 2014;69(1):155-61. 